\title{
Misión Chardon y la modernización agrícola en el valle geográfico del río Cauca (Colombia)
}

\author{
Olga lucía Delgadillo y Víctor Hugo Valencia
}

\begin{abstract}
PALABRAS CLAVE: valle del Cauca, Chardon, modernización agrícola, historia ambiental.
\end{abstract}

CÓDIGOS JEL: Q1, Q5, Q150, 013.

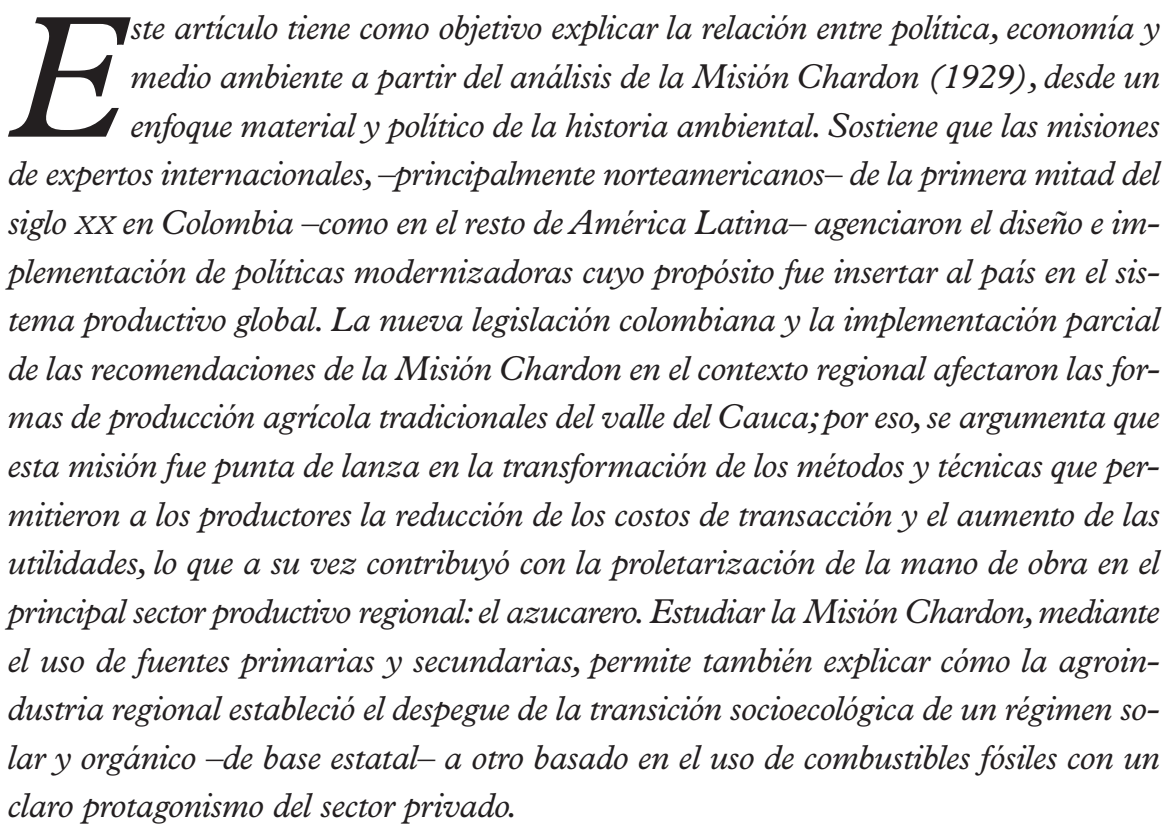




\title{
The Chardon Mission and Agricultural Modernization in the Cauca River Valley of Colombia
}

\author{
KEYWORDS: Valle del Cauca, Chardon, agricultural modernization, \\ environmental history.
}

JEL CODES: Q1, Q5, Q150, 013.

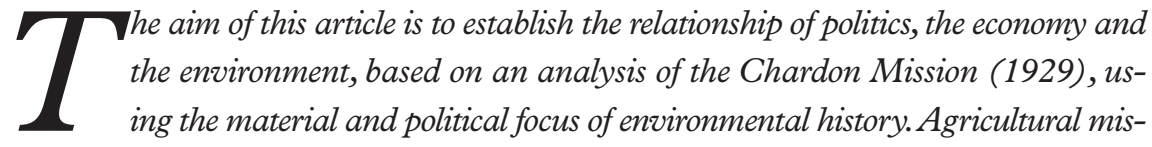
sions involving international experts, mainly from North America, in Colombia and throughout Latin America during the first half of the twentieth century led to the design and implementation of modernizing policies intended to include the country in the global production system. New Colombian legislation and partial implementation of the Chardon Mission recommendations for the regional context affected traditional agricultural production in the Cauca Valley. It can be argued that the mission spearheaded the transformation of the methods and techniques that allowed producers to reduce transaction costs while increasing outputs. This in turn contributed to the proletarization of the workforce in the main sector of regional productivity: the sugar industry. Using primary and secondary sources to study the Chardon Mission, we can better understand how regional agro-industry began the socioecological transition from a state-based solar and organic regime to one dominated by the private sector and the use of fossil fuel.

Recepción: 2018-09-02 - Revisión: 2019-04-08 - Aceptación: 2019-04-09

Olga Lucía Delgadillo [orcid.org/0000-0001-6887-4423] es ingeniera agrónoma y doctora en Estudios Ambientales y Rurales. Trabaja como profesora en el Departamento de Ingeniería Civil e Industrial de la Pontificia Universidad Faveriana. Domicilio para correspondencia: cl 18, $n .^{\circ} 118-250,760031$ Pance, Cali (Colombia).C.e.:odelgadillo@javerianacali.edu.co

Víctor Hugo Valencia [orcid.org/0000-0003-2780-0211] es comunicador social, periodista, magister en Estudios Políticos y doctor en Comunicación. Trabaja como profesor en el Departamento de Comunicación y Lenguaje de la Pontificia Universidad faveriana. Domicilio para correspondencia: cl 18, n. ${ }^{\circ} 118-250,760031$ Pance, Cali (Colombia). C. e.: vhvalencia@javerianacali.edu.co 


\section{INTRODUCCIÓN}

A mediados del siglo XIX, cuando el liberalismo ilustrado (Marquardt, 2009: 128) emergía como ideología dominante del desarrollo en América Latina, las políticas estatales de libre comercio instaban a cada una de sus naciones a producir y a vender los bienes y productos que les representaban una ventaja comparativa frente a otras economías (McCook, 2002). La demanda europea y norteamericana de materias primas latinoamericanas (nitratos, henequén, petróleo y caucho) y bienes de consumo (café, trigo, azúcar y carne de res), impulsó el boom agroexportador de finales del siglo XIX, el mismo que se mantendría hasta la tercera década del siglo xx. En 1913, trece de los veinte países latinoamericanos tenían más de la mitad de sus exportaciones concentradas en un solo producto, que facturaban casi exclusivamente a Gran Bretaña, Estados Unidos, Francia y Alemania. Sin embargo, la mayoría de dichas exportaciones se hacían desde países como Argentina y Brasil, que proporcionaron más de la mitad de todos los bienes exportables, y que junto a Chile, Cuba y México suministraban el $80 \%$ de las ventas de América Latina al exterior (Topik \& Wells, 1998).

Por la misma época, la economía colombiana estaba basada en la producción agraria tradicional de haciendas de ganadería extensiva en combinación con cultivos que abastecían el mercado alimentario nacional; oscilando entre el nuevo modelo liberal y la reconstrucción de las bases coloniales de la economía regional (González, 2001). A comienzos del siglo xx, el Estado colombiano promovió la industrialización e intensificación agrícola con el ánimo de entrar a competir en el mercado internacional.

Fue así como las misiones de expertos internacionales empezaron a jugar un papel determinante para la consolidación de los emprendimientos agroexportadores (Vera, 1996: 129-150): con este tipo de intervenciones especializadas se esperaba examinar la situación real de los recursos naturales y, al mismo tiempo, establecer los derroteros que servirían de insumo para que se pudiesen desarrollar nuevos cambios en [la] política administrativa (Chardon, 1930: 6) de los recursos, tanto en la escala del capital financiero como en factores políticos y ambientales.

Las misiones técnicas europeas y norteamericanas fueron comunes en toda América Latina en esta época, como las provenientes de Bélgica, la inglesa de Manchester, o la norteamericana Kemmerer. Aparentemente, a dichas misiones las animaba un espíritu transnacional de cooperación apolítica, por lo que llegaron casi irrestrictamente a distintos confines de Latinoamérica y del mundo. 
Para el caso colombiano, en 1906 Charles Deneumostier dirigió la Misión Belga de agricultura -contratada por el Ministerio de Agricultura-, cuyo cometido era buscar el incremento del comercio de abonos y herramientas agrícolas entre los dos países (Broeck \& Molina, 1997: 47-71). Tiempo después, el presidente Pedro Nel Ospina contrató la Misión Kemmerer en 1923 (Drake, 1989: 30-75) y la Misión Manchester (International Cotton Federation) en 1926. La primera se ocupó de la modernización de las finanzas y la Administración pública, para lo que planteaba remplazar el modelo económico agrícola por uno industrial, con centros de operación en las principales ciudades del país. La segunda buscó promover el cultivo y aprovechamiento del algodón, aconsejando la creación de un Servicio Nacional del Algodón (Cotton Service) en coordinación con los gobiernos nacional y departamentales, y recomendando el establecimiento de fincas para la experimentación con métodos modernos de cultivo, a manera de campos demostrativos (Pearse, 1926: 95-96, 106-107). La misión más destacada, por lo que significó para el futuro socioecológico del valle geográfico del río Cauca, fue la dirigida por el puertorriqueño Carlos Eugenio Chardon, entre 1929 y 1930. Su propósito era realizar un survey (reconocimiento agropecuario) del territorio regional que permitiría diseñar un paquete de políticas para modernizar el sector agropecuario, con las que se esperaba transformar y aumentar la agencia productiva a fin de vincular la región al sistema productivo global.

Este tipo de acciones políticas, a la postre, terminaron incidiendo no sólo en la economía regional y nacional, sino en las transformaciones biofísicas del territorio ${ }^{1}$, que a su vez afectaron las condiciones de vida de los vallecaucanos. De acuerdo con esta última consideración, este artículo se enmarca en dos de los tres posibles enfoques de la historia ambiental: el material, que hace hincapié en el desarrollo económico y tecnológico ocupándose de los cambios en los entornos físicos y biológicos para explicar cómo estos afectan a las sociedades humanas; y el enfoque político, que considera las leyes y políticas de Estado en su relación con el mundo natural (McNeill, 2005: 12-25). En este contexto cabe la pregunta sobre cómo incidieron las recomendaciones de la Misión Chardon en la configuración territorial del valle geográfico del río Cauca durante el siglo Xx.

El objetivo de este artículo es explicar la relación entre política, economía y medio ambiente a través de una aproximación analítica a la Misión Chardon. Se parte de la premisa de que las misiones internacionales desarrolladas en la primera mitad del siglo $\mathrm{xx}$ propiciaron el diseño e implementación de políticas públicas a escala nacional y regio-

1. Este es un concepto polisémico y controvertido. Esta investigación se acoge a las perspectivas que plantean que el territorio es el espacio físico e histórico donde se relacionan los miembros de una sociedad y, por lo tanto, se construye y se transforma material y simbólicamente en un proceso cultural (PALACIO, 1998). 
nal, cuyo fin fue la modernización productiva del agro colombiano. Estudiar la Misión Chardon permite explicar por qué esta se ha considerado la primera política pública regional que, en la mediana duración, generó procesos de innovación y cambio tecnológico en el valle geográfico del río Cauca. Dichos procesos transformaron velozmente la explotación agropecuaria tradicional por un modelo de producción agropecuaria de tipo comercial y, posteriormente, por uno agroindustrial, que fueron la fase de despegue de la transición socioecológica desde un régimen solar y orgánico de base estatal a otro basado en el uso de combustibles fósiles con claro protagonismo del sector privado.

El potencial productivo derivado de las diversas condiciones biofísicas de esta región, junto al afán de las élites vallecaucanas por modernizar sus prácticas productivas para la inserción del país en el mercado mundial, implicaba adelantar una discusión especializada que articulase las lógicas de las ciencias agropecuarias con las de la economía y la política. Por eso, las recomendaciones de las misiones técnicas facilitaron el diseño de políticas públicas que permitirían la consolidación del sector y la industria agropecuaria, primero en la región y, posteriormente, en el país.

\section{EL VALLE DEL CAUCA}

Este departamento está ubicado al suroccidente de Colombia, y es considerado una de las regiones más ricas y de mayor desarrollo del país. Tiene una superficie total de $21.195 \mathrm{~km}^{2}$, lo que representa el 1,5\% del territorio nacional. Se caracteriza por su diversidad biofísica derivada de sus tres regiones fisiográficas: las vertientes de las cordilleras central y occidental (dos de los tres ramales en que se dividen los Andes al entrar a territorio colombiano) (52,7\%), la hoya del alto Cauca (14\%) y la costa pacífica $(33,2 \%)$. La hoya del alto Cauca es una zona con una diversidad ecosistémica que cubre zonas de vida entre los 900 y los $4.200 \mathrm{msnm}$ en la cordillera occidental y 5.000 en la cordillera central. La parte plana (zona más clara en el mapa, atravesada de sur a norte por el río Cauca) corresponde a uno de los cinco enclaves del ecosistema de bosque seco tropical en Colombia, uno de los más escasos y transformados del país (Mapa 1).

Esta diversidad de relieves representa gran variedad climática y edáfica. La llanura del Pacífico presenta precipitaciones pluviales que llegan a los $5.000 \mathrm{~mm}$ al año con un régimen pluviométrico monomodal. El área plana tiene un régimen bimodal, con dos períodos de mayores lluvias (de marzo a mayo y de septiembre a noviembre) y con temperatura promedio de $24^{\circ} \mathrm{C}$. Mientras que el área montañosa de ladera tiene períodos más amplios y de abundantes lluvias, que van de marzo a junio y de septiembre a diciembre. 
MAPA 1

Departamento del Valle del Cauca (Colombia)

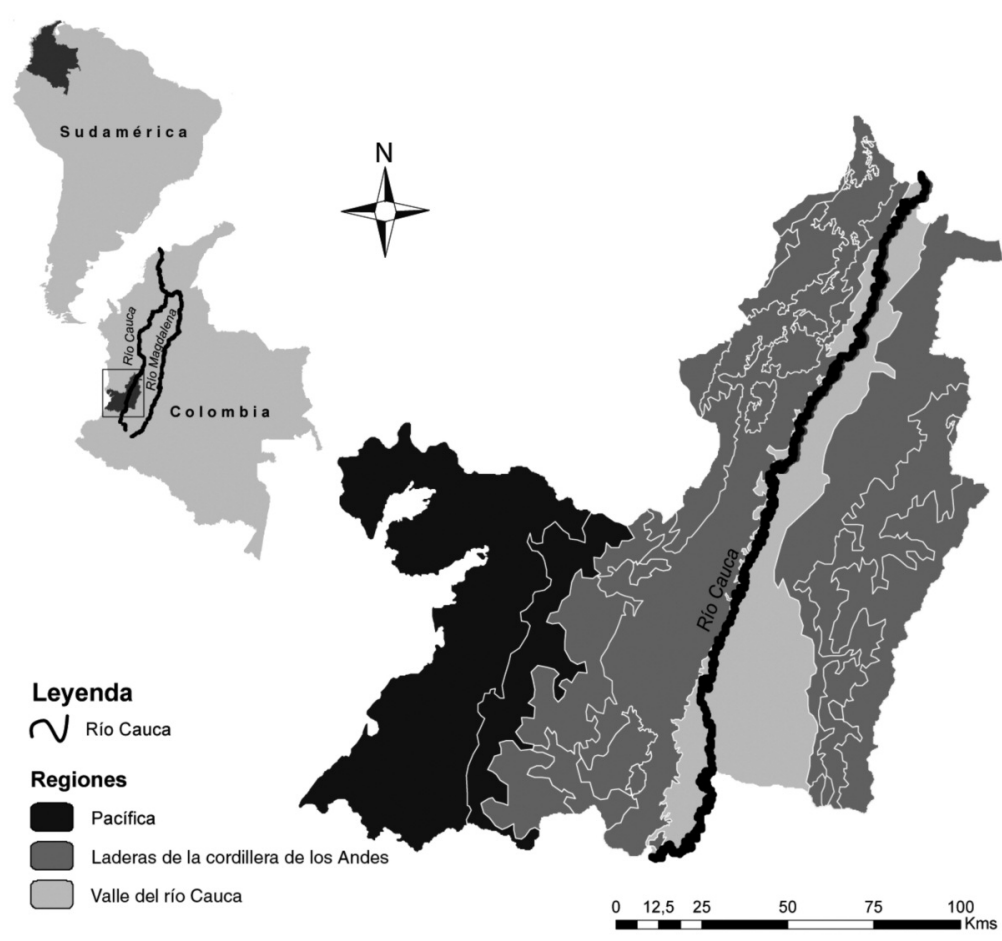

Fuente: María José La Rota.

\section{LA REGIÓNY LA EXPLOTACIÓN AGROPECUARIA TRADICIONAL}

Aunque en el siglo XIX, y desde la época colonial, la propiedad de la tierra del valle del Cauca fue de tradición latifundista, la extinción de los mayorazgos, la transformación de las relaciones de trabajo en la hacienda y la multiplicación de caminos fueron dando lugar a la reproducción de pequeños fundos y a la fragmentación de las antiguas haciendas. El sistema de haciendas propició el monopolio de tierras, mantuvo el trabajo de los esclavos como principal forma de explotación agrícola y ocupó gran parte del territorio en la producción de ganado. A mediados del mismo siglo XIX, con las reformas liberales, la economía nacional se volcó hacia el modelo agroexportador y comenzó a crecer sistemáticamente a través del cultivo y comercialización del café.

La ampliación, construcción y mejoramiento de la infraestructura favorecieron la disponibilidad de insumos básicos e insumos agrícolas. La navegación a vapor por el río Cauca inició en 1888. El río y la mayoría de sus afluentes se constituyeron en ejes viales 
para el transporte de personas y productos agropecuarios desde unidades productivas pequeñas hacia los mercados, a través de más de veinte puertos de embarque y desembarque (CVC, 2004: 32). Por la misma época se inició la construcción del ferrocarril (1878) que uniría el puerto de Buenaventura con el centro del país; y poco después, la apertura del canal de Panamá (1914) acrecentó las ventajas del puerto y extendió el ferrocarril del Pacífico hacia el norte.

La ganadería extensiva seguiría siendo la principal actividad económica del valle hasta mediados del siglo xx: el hato ganadero (compuesto por bueyes, caballos y mulas) constituía un importante renglón productivo para los hacendados, pues era imprescindible para conformar las recuas que movilizaban mercancías, implementos agrícolas y cosechas. Esta actividad dependía de medianas y pequeñas propiedades asentadas en las estribaciones de la cordillera central, y en inmediaciones de los poblados con producción para autoconsumo y exportación de productos agrícolas, como café, tabaco, cacao y arroz. El cultivo de la caña de azúcar estuvo asociado a un elevado número de trapiches, tanto de fuerza hidráulica como a vapor y de tracción animal, con producciones importantes de panes de azúcar, panela, miel y melaza (Mallama, 1996: 30).Ya en 1925 la caña de azúcar hacía parte del sistema productivo, con plantíos a pequeña y mediana escala, con el primer ingenio azucarero moderno, ubicado en el municipio de Palmira (zona plana del departamento), y con más de cuarenta trapiches paneleros.

Las fincas campesinas en la zona plana, reducidas en área y cantidad, funcionaban en su mayoría como sistemas agroforestales, conservando como sombrío algunos de los árboles originales de los antiguos bosques ribereños, y combinados con cultivos de frutales, hortalizas, plantas aromáticas y artesanales, y cercos vivos. La producción agrícola alternaba con la cría de animales de granja, como gallinas criollas, patos, pavos domésticos y cerdos, tanto para el consumo familiar como para la venta en los mercados locales.

Estas condiciones de diversidad biológica y cultural fueron desestimadas por los tomadores de decisiones de los niveles local, regional y nacional, quienes, justificados por las doctrinas del progreso y la modernización de los sistemas productivos provenientes de otras latitudes, abrieron sus oídos a las recomendaciones de expertos extranjeros.

\section{CARLOS E. CHARDON: ITINERARIO CIENTÍFICO Y MISIÓN AGRÍCOLA EN COLOMBIA}

Carlos Eugenio Chardon (1897-1965) nació en Ponce (Puerto Rico) y obtuvo su grado de licenciado y máster agropecuario de la Universidad de Cornell (Estados Unidos). Al 
regresar a Puerto Rico en 1921, se vinculó como fitopatólogo en la Estación Experimental Agrícola Insular Rio Piedras (Universidad de Puerto Rico) y en 1923 fue comisionado de Agricultura (San Juan), cargo que ocupó hasta 1930. Allí tuvo oportunidad de trabajar en el mejoramiento de cultivos de gran importancia económica, como el tabaco y la caña de azúcar (Kern, 1965). En esta posición, Chardon participó en la identificación del insecto vector de la epidemia del mosaico en la caña, posiblemente la primera gran crisis agrícola en América Latina. El éxito de los científicos en el control de esta enfermedad en la década de 1920 les confirió gran influencia decisional en todo el Caribe y luego en gran parte de Latinoamérica. Luego, siendo comisario de Agricultura y Trabajo de Puerto Rico, Chardon inició sus viajes como consultor por varios países, entre ellos Cuba, Colombia, Venezuela y República Dominicana. La misión de Chardon consistió en adaptar el conocimiento científico de América del Norte al contexto social, económico y político de América Latina. A finales de la década de 1920, sus dos proyectos principales fueron construir una Escuela Panamericana de Posgrado de Agricultura Tropical en Puerto Rico y establecer una red nacional de investigación agrícola en Colombia (McCook, 2002: 106).

Chardón llegó a Colombia por primera vez en 1926, contratado por la gobernación de Antioquia para reorganizar la Escuela Superior de Agronomía (Chardon, 1941: 71, 337). En aquella ocasión, se ocupó de tres actividades agrícolas: experimentación, enseñanza agrícola y vulgarización agrícola; suprimió los estudios de veterinaria y cambió el título de Agrónomo y Médico Veterinario, conferido hasta esa época, por el de Ingeniero Agrónomo ${ }^{2}$. También identificó la enfermedad denominada gomosis en la caña de azúcar, e introdujo durante los tres años siguientes nuevas variedades de caña provenientes de Puerto Rico.

Aquella visita coincidió con la promulgación de la ley 74 de 1926 sobre fomento a la agricultura y a la inmigración. A partir de dicha ley el Gobierno conservador en empalme (Ospina/Abadía) quedaba habilitado para organizar un Instituto Agrícola Nacional que serviría de base a los estudios superiores de agronomía y agricultura, y sería el centro de investigación y consulta en cuestiones agrícolas del país. El Gobierno también se comprometía a fundar tres estaciones experimentales nacionales, lo más cercanas posible a la capital de la República, en pisos térmicos correspondientes a la zona fría, templada y cálida. Dichas estaciones servirían a la vez de centros de experimentación científica y de práctica para los estudios que se hicieran en el instituto de agronomía y veterinaria.

El marco legal recién creado le permitiría a Colombia seguir los pasos de la investigación europea, la cual había demostrado desde 1850 que la ciencia agrícola podía pro-

2. Museo Entomológico, http://ciencias.medellin.unal.edu.co/museos/entomologico/ 
ducir beneficios prácticos sustanciales sin demandas excesivas en mano de obra y capital, usando para ello las estaciones experimentales agrícolas. Aunque esta influencia duró poco como consecuencia de las dos guerras mundiales, que dieron paso al dominio de Estados Unidos ${ }^{3}$.

En este contexto, Carlos Holguín Lloreda, gobernador del departamento del Valle del Cauca (1927-1929), presentó en 1928 al entonces ministro de Relaciones Exteriores, Enrique Olaya Herrera, una propuesta que exhortaba su intervención ante el Gobierno norteamericano para solicitar la cooperación de expertos que estudiasen las condiciones agrícolas y pecuarias del departamento. Para ello, se requería de cabildeo ante Washington y San Juan de Puerto Rico, donde funcionaba el mayor y más importante centro de investigación agropecuaria del circuito norteamericano: el recinto Mayagüez-Estación Experimental Agrícola ${ }^{4}$, en el que Chardon participaba activa y constantemente.

La gestión del ministro fue apoyada y acompañada por Ciro Molina Garcés, Rafael Ignacio Gómez (cónsul de Colombia en San Juan de Puerto Rico) y por Carlos Durán Castro $^{5}$, quien sería luego el primer director de la Estación Agrícola Experimental de Palmira. Como resultado de la intervención diplomática, el gobierno departamental en cabeza del sucesor de Holguín, Tulio Raffo, logró que Chardon aceptase ser el director de la empresa evaluadora.

La Misión Puertorriqueña, conformada por Chardon y cuatro profesionales más (un veterinario y zootecnista de la Universidad de Pensilvania, un patólogo vegetal, máster de la Universidad de Cornell, un agrónomo y un secretario, todos norteamericanos) se concentraría en la discusión y estudio general de los problemas pecuarios, incluyendo las enfermedades y su control, aclimatación y cruce de razas exóticas de ganado, así como tam-

3. Las dos guerras mundiales produjeron una transformación en todo el sistema que regía las relaciones entre las naciones. Europa occidental, centro del poderío mundial durante siglos, estaba físicamente destrozada y económicamente postrada. Ante el indefectible declive de las potencias europeas, fueron Estados Unidos y la Unión Soviética los países que emergieron como las principales potencias hegemónicas en el nuevo orden internacional de la segunda posguerra (McCook, 2002: 24). La influencia norteamericana que se había instaurado en América Latina a comienzos del siglo XIX con la defensa del panamericanismo, a través de la doctrina Monroe, se reafirmaba con el corolario del presidente Theodore Roosevelt en 1904 (CARBOnE, 2010). A comienzos del siglo Xx en el Caribe ya existían cinco estaciones de investigación norteamericanas estables, tres en Cuba y dos en Puerto Rico, que fueron icónicas para el resto de América Latina.

4. Estación Experimental Agrícola, https:/www.uprm.edu/eea/nosotros/

5. Ciro Molina Garcés (1891-1953) y Carlos Durán Castro (1897-1993), fueron funcionarios estatales regionales y nacionales. El primero fue miembro de dos de las familias políticas y empresariales más destacadas del departamento, reconocido empresario pionero de la modernización del agro regional, quien era entonces el primer secretario de Industrias del departamento del Valle. 
bién la discusión y estudio general de los problemas agrícolas del departamento desde el punto de vista económico. De todo ello debía derivarse recomendaciones prácticas que permitieran comprender los problemas del cultivo de caña de azúcar, tabaco, café y algodón, y someter a un plan completo de organización a la Estación Experimental Agrícola de Palmira.

La misión encontró un país convulsionado. A finales de la década de 1920, y luego del periodo de hegemonía conservadora, volvía un liberal a la presidencia de Colombia (Enrique Olaya Herrera) y aparecía de manera simultánea el Partido Socialista, lo que acentuó la confrontación política y desencadenó nuevos brotes de violencia partidista. Para colmo, la convulsión política vino acompañada de una grave crisis económica (Palacios, 2011: 99). El descenso en el precio del café, principal actividad económica del país, implicó una importante caída en los ingresos externos y empeoró la situación financiera nacional, agudizada por los efectos de la crisis mundial tras la caída de la Bolsa de Nueva York. Entre tanto, los empresarios y el cuerpo diplomático norteamericano intentaban intervenir en los asuntos internos del país; no solo para proteger sus intereses económicos a través de la expansión de sus mercados (Ardila, 2013: 175, 180), sino para frenar la posible propagación del comunismo.

\section{CIENCIA, AGRICULTURA Y MEDIO AMBIENTE: LOS EFECTOS DE LAS RECOMENDACIONES DE LA MISIÓN}

La misión a lo largo del informe hace referencia a lo que ellos llaman el medio natural que encontraron al llegar al Valle del Cauca: la parte plana que se extiende en grandes llanuras a uno y otro lado del caudaloso Cauca, terrenos alfombrados por el «pará» y la «yerba guinea» y cubiertos de trecho en trecho por los restos de la vegetación original de bosque, enorme, abigarrada y espesa que desordenadamente motea su verdor, denuncian su admirable feracidad. Los potreros eran muy semejantes a los vistos por ellos en las islas de Santo Domingo y Puerto Rico, cubiertos con un nutrido pasto común y natural, y árboles de diversas variedades que crecían naturalmente; pero sobre todo, admiraban los bosques de guaduas que le daban majestuosidad al valle (Chardon, 1930: 65, 126).

En la introducción del informe final, Chardon reconocía lo arriesgado de sus predicciones, al punto que advertía de poder incurrir en errores graves, pero al mismo tiempo aseguraba:

[...] nos aventuramos a declarar que las condiciones naturales del Valle del Cauca son tan privilegiadas, que un esfuerzo coordinado del gobierno y los elementos de 
producción a base de un programa agresivo, cooperativo y constante de mejoramiento agrícola, daría realización plástica al nombre con que lo bautizó Humboldt hace más de un siglo: El paraíso de América (Chardon, 1930: 17).

Sus observaciones posteriores a la inspección de 34 haciendas en el valle geográfico del río Cauca (Chardon, 1930: 42) le permitieron concluir que existían malas prácticas agrícolas y ganaderas, y evidenció el mal estado de la mayoría de los cultivos, ganados e instalaciones agropecuarias regionales. La misión mostró cómo las técnicas de cultivo no optimizaban ni los suelos, ni la mano de obra, ni mucho menos las condiciones geoambientales que el valle proporcionaba.

Esto equivalía a sostener que la explotación económica regional estaba siendo no solo desperdiciada sino desaprovechada casi por completo. Uno de los temas centrales abordados por la misión fue el del cultivo de la caña de azúcar, que junto a los problemas pecuarios evidenciaba la necesidad urgente de la modernización de las explotaciones agropecuarias regionales (Chardon, 1930: 123) y la organización de la Estación Experimental de Palmira. Así, la misión se acoplaba a la iniciativa gubernamental de crear políticas agrarias de carácter científico (Valencia \& Carmona, 2015: 281-295) en beneficio de la modernización nacional, lo que redundaría, a mediano plazo, en la inserción al sistema productivo global.

\subsection{La caña de azúcar}

El estudio del cultivo de la caña de azúcar fue el tema que más interesó a la misión, puesto que los técnicos puertorriqueños veían grandes posibilidades de aumentar la producción con base en su experiencia. La atención que despertaba la caña de azúcar y sus derivados no era nueva: desde la colonia el cultivo de esta planta, junto con la minería, constituían las fuentes de sustento económico para gran parte del continente americano (Stern, 1987: 3-58).

Sobre las potencialidades de la caña, Chardon anotó que este cultivo era una actividad agrícola en la cual se conjugaban estrategias económicas y políticas, pues un derivado como el azúcar refinada era uno de los artículos de primera necesidad más usados en el mundo, no hay país que no produzca o importe, pues directa o indirectamente forma parte de la alimentación moderna (Chardon, 1930: 122). Enfatizó que en el azúcar había un negocio que podía arrojar buenas utilidades, siempre que las condiciones económicas y medioambientales fueran favorables; por lo que sugería que se pensara una legislación acorde para facilitar su explotación (Ibid.: 129). La Misión concluyó que el 
cultivo de la caña de azúcar se hallaba en el periodo extensivo de su explotación ${ }^{6}$ y señaló que los principales problemas estaban asociados a la gran distancia de siembra que había entre las cañas, la preparación superficial y deficiente de la tierra, y el regadío inadecuado y rudimentario (Ibíd.: 133-146); lo que causaba grandes desperdicios de agua $^{7}$.

La producción de azúcar en el Valle del Cauca era muy baja, apenas 0,44 toneladas por plaza (Cock, 1999: XII), comparada con Java y Puerto Rico que obtenían 8 toneladas de azúcar por plaza ${ }^{8}$ y Hawái donde se cosechaban en promedio 11 toneladas (Chardon, 1930: 125-126). La baja productividad hacía que el rendimiento comercial de los derivados de la caña en el valle no se explotasen al máximo, lo que impulsó a Chardon a estimar que si del área total plana del valle geográfico se utilizasen $4.000 \mathrm{~km}^{2}$ solamente para el cultivo tecnificado de caña, se podrían obtener en promedio 50 toneladas de caña por plaza (78 ton/ha), lo que equivaldría a un rendimiento del 10\% en azúcar, es decir, 5 toneladas por plaza cultivada ${ }^{9}$. Estas estimaciones les permitieron a los técnicos de la misión visualizar el potencial productivo del valle geográfico del río Cauca en el ramo azucarero, pero fueron cautos al afirmar: no deseamos insinuar que el Valle pueda llegar a desarrollar una producción azucarera de tal magnitud (Ibid.: 125). Con esto dejaban la decisión en manos tanto de las autoridades gubernamentales departamentales como del empresariado regional.

A partir de las observaciones de la misión, la región inició la ejecución de un plan piloto de siembra de caña de azúcar en los ingenios Manuelita y Providencia, mediante el cual se redujo considerablemente la distancia entre plantas para darle mayor uso a la tierra. Este procedimiento exigió procesos de desarrollo tecnológico para modificar los sistemas de riego, una medida que resultaba crucial para las cadenas productivas cañeras,

6. El área sembrada se calculó en cerca de 9.950 hectáreas, insuficientes para el consumo interno, lo que obligó a importar, en 1928, 1.800 toneladas de azúcar por Buenaventura.

7. Para entonces, era de conocimiento técnico común que las condiciones de humedad inciden directamente sobre la calidad y cantidad de azúcar que se puede extraer de cada plaza cultivada; por ello, en el Ingenio Manuelita se llevaban registros históricos, en los que se reportaba la aplicación de riegos del orden de $20.000 \mathrm{~m}^{3} / \mathrm{ha}^{-1} / \mathrm{año}^{-1}$ o mayores para garantizar un suelo con un alto contenido de humedad -a capacidad de campo- sin que primase el concepto de suplir los requerimientos hídricos del cultivo.

8. Una plaza equivale a 0,64 hectáreas.

9. Cálculos estimados con base en el área territorial del departamento del Valle que equivalía, según el Boletín de Estadística Departamental n. ${ }^{\circ}$ vIII de 1930, a $20.620 \mathrm{~km}^{2}$, de los cuales 13.800 $\mathrm{km}^{2}$ constituían el área productiva agrícola, pasturas y dehesas, y de estas, 4.600 correspondían a la parte plana. Cada kilómetro cuadrado tiene 156,25 plazas, de manera que los 4.000 equivalen a 625.000 plazas. 
pues, tal como indicaron los técnicos, la calidad del azúcar dependía directamente de la regulación del agua. La modificación del sistema de riego exigía considerar rigurosa y estrictamente las condiciones meteorológicas de la región (pluviosidad y temperatura), fundamentales para el proceso productivo, dada la marcada influencia que estas tenían sobre las cosechas, en cultivos como la caña de azúcar y el algodón.

Los técnicos reportaron que hasta 1928 muy poco se había hecho en el estudio de tan importantes factores para el desarrollo de la agricultura departamental; solo el Ferrocarril del Pacífico había realizado algunas observaciones verificadas de la precipitación pluvial durante unos pocos años. A pesar de la falta de métodos científicos precisos, los expertos contaron con una ventaja para adelantar sus estudios piloto, pues el ingenio Manuelita tenía una serie completa de registros de las precipitaciones y de las temperaturas de los primeros 29 años del siglo Xx, aspecto mencionado en el informe final. Esta situación denotaba el valor que Santiago Eder, al igual que Hernando Caicedo y otros empresarios que les eran contemporáneos, le otorgaban a la exactitud derivada de posturas de carácter técnico-científicas ${ }^{10}$.

Las recomendaciones para el mejoramiento del cultivo también incluían la necesaria introducción y desarrollo de nuevas variedades, el uso de tractores tipo oruga (Caterpillar) e implementos como el arado Killifer $n .^{\circ} 25$ en la preparación del suelo para la siembra y la adecuación del sistema de regadío según el método Hawái (Chardon, 1930: 146165) (véase Fotos 1 y 2).

Aunque Chardon preconizaba que el desarrollo de la región debía partir de un ordenamiento del territorio basado en la modernización científica de las explotaciones agropecuarias, también hacía énfasis en la diversificación de la producción y en el mejoramiento de la disponibilidad de alimentos. Según la misión, Colombia debía iniciar un proceso de seguridad alimentaria con base en los productos agropecuarios más relevantes y con ventajas comparativas, teniendo en cuenta el medio ambiente y el mejoramiento de las condiciones económicas de los campesinos. En las recomendaciones incluían la formación de sociedades cooperativas adaptables con la industria azucarera, las cuales podían conservar y hasta estimular la formación y conservación de pequeñas propiedades, lo que redundaría en una mejor y más amplia distribución del capital y, por tanto, fomentaría la verdadera prosperidad de un país (Chardon, 1930: 130).

10. Santiago James Eder fue el gestor del Ingenio Manuelita, el primero en ser fundado en la región; Hernando Caicedo fue el de los ingenios Riopaila y Central Castilla, empresario que además fundó la fábrica de dulces Colombiana SA. 


\section{FOTOS 1 y 2}

Primeros tractores International y cultivo de caña con riego, 1929
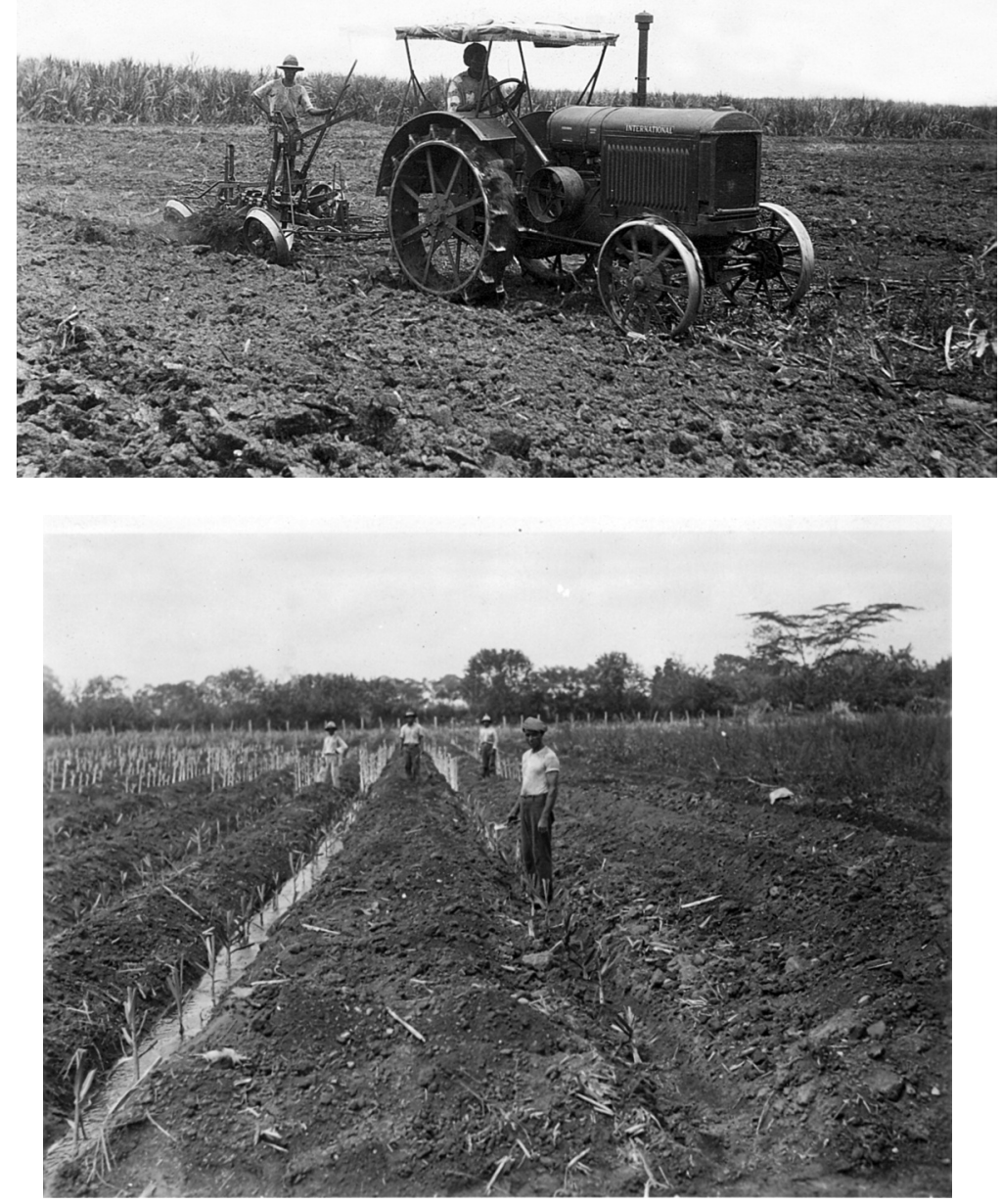

Fuente: Archivo Histórico del Ingenio Manuelita SA (AH Mansa), Palmira.

\subsection{La ganadería}

En cuanto a la producción ganadera -principal actividad económica regional- Chardon describió que en el valle geográfico del río Cauca existía para el momento del survey una ganadería compuesta básicamente por: 
[...] ganado vacuno indígena de temperamento vivo y nervioso, sobrio, que soportaba fácilmente los grandes calores, la sequía, la alimentación grosera en la época de verano y resistente a grandes jornadas [...] Tipo de carne con poca producción de leche [...] ganaderías con cruzamientos de este ganado con diversas razas exóticas, como Aberdeen Angus, Durham y Charollais, entre las de carne; Holstein Fresian, como productores de leche, y Blanco Orejinegro, Normando y Red Poll para doble propósito, pero los resultados no han sido todo lo que el ganadero esperaba. El Cebú, llamado también «indio", no entraba en los tipos anteriores, sino que se constituia por sí en una raza de tiro (Chardon, 1930: 42-49).

También apuntaba Chardon la falta de prácticas productivas eficientes, asociadas con la división de potreros, y la ausencia de organización de la industria ganadera, circunstancias que según su informe no permitían la clasificación de los animales en especies, razas, edades y sexos, como lo planteaban las técnicas pecuarias de entonces (Chardon, 1930: 45). La mayoría de las áreas dedicadas al pastoreo, bien con pastos nativos (caracterizados por su escasa producción de biomasa y pobre calidad nutricional), o con pastos introducidos, se manejaban mal durante las fases de establecimiento y producción, lo que no permitía producciones estables. Concluía el informe que las variaciones climáticas propias del ecosistema, por la alternancia de largos periodos de lluvia y épocas prolongadas de sequía, reducían la oferta forrajera.

La misión reconoció el gran valor del ganado nativo y su potencial como espléndida base para cruces con razas finas traídas del exterior, lo que permitiría obtener tipos uniformes y muy superiores de ganado, tal y como había sucedido en Estados Unidos, Argentina y Uruguay, con magníficos resultados, ejemplo que debía seguir elValle del Cauca (Chardon, 1930: 8).

La recomendación tal vez más contrastante fue la de trasladar la ganadería a las partes altas, regiones muy apropiadas para ella y de menor valor para los cultivos, para así reservar la zona plana para actividades agrícolas, privilegiando la producción de bueyes y caballos (a base de cruzamientos con el caballo Prusiano y el Morgan) sobre la de ganado de carne. De este modo, se incidiría positivamente en el crecimiento productivo del agro, lo que era posible mediante el arado de tracción animal, técnica previa a la incorporación de maquinaria agrícola (véase Fotos 3 y 4).

Estas recomendaciones, aunque parecen remitirse exclusivamente al rendimiento ganadero, fueron fundamentales para la evolución de la cultura alimentaria de la población regional. Lograr que la carne fuera de mejor calidad significaba para el Estado colombiano aumentar las utilidades de las empresas ganaderas y mejorar las prácticas de higiene, para 
FOTO 3 y 4

Ganadería y alce de caña con grúa mecánica tirada por bueyes, 1929
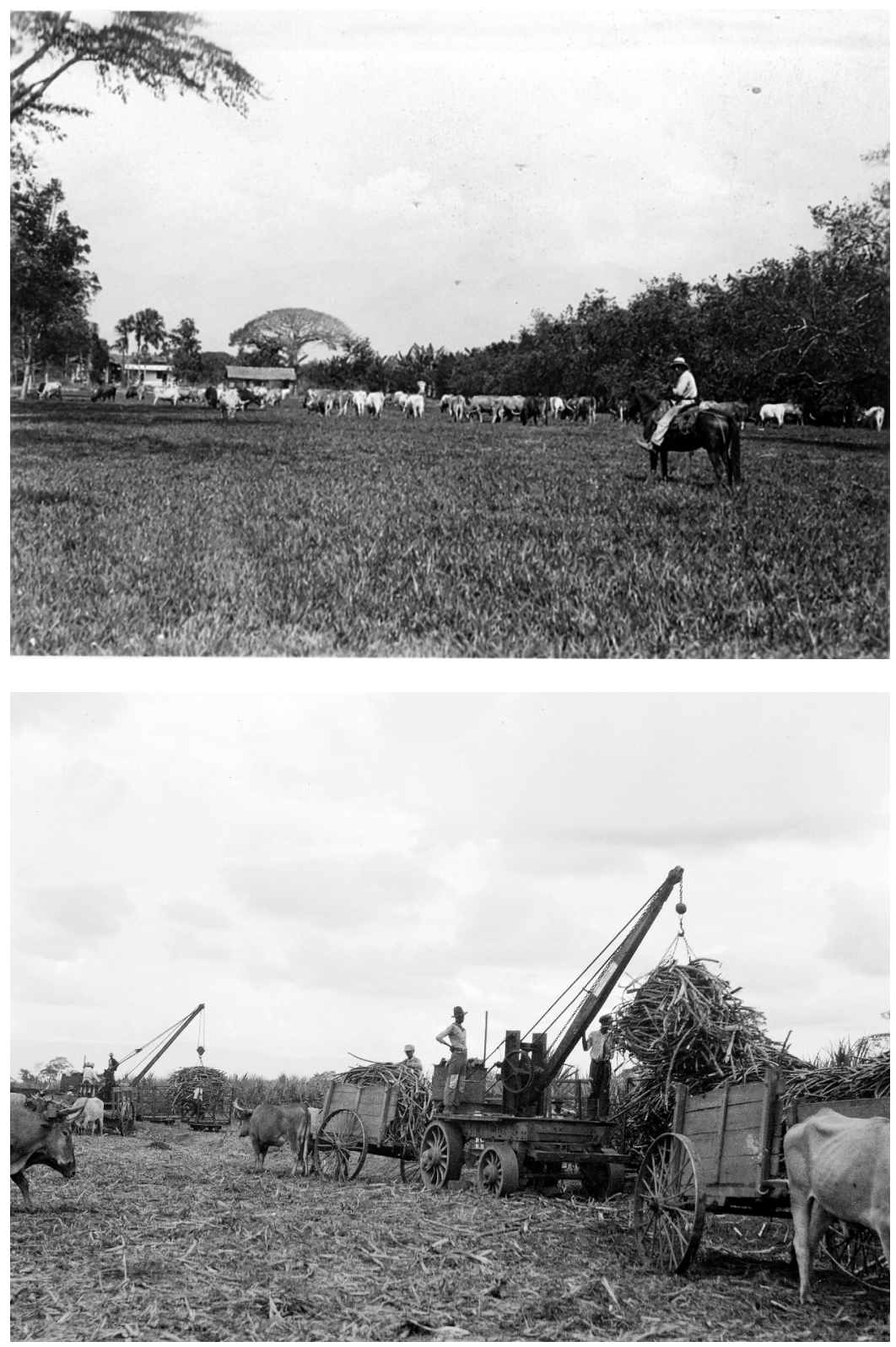

Fuente: AH Mansa, Palmira. 
alcanzar la transformación moral de la población ${ }^{11}$. Alimentar a una población urbana en crecimiento, especialmente en Bogotá, Medellín y Cali, en los albores de la industria textil, era un imperativo, por lo que se insistía en la necesidad de que el Gobierno prestara más atención a las clases trabajadoras y a sus prácticas higiénicas, pues de ellas dependía el progreso (Bolívar, 2008: 253; Flórez, 2008: 376).

\subsection{La estación experimental de Palmira}

La resolución de los problemas encontrados requería que los trabajos agrícolas se dividieran en tres líneas de actividad para alcanzar el anhelado progreso que esperaba el país: la protección del agro, la experimentación agrícola y el fomento a la agricultura. La segunda línea de actividades que ejecutar fue crucial para el progreso agrícola. Los logros del conocimiento tecnocientífico de los siglos XVIII y XIX no habrían tenido alojo en la agricultura práctica, en el contexto de la segunda revolución agrícola, si su irradiación no se hubiera generalizado. Los cultivadores hicieron su transición hacia lo moderno en medio de un proceso de transformaciones en el orden económico y social, a través de la extensión agrícola, la cual comprendía, tanto las granjas con fines demostrativos como las estaciones experimentales para investigar y propagar nuevos conocimientos aplicados (Arango, 2005: 15).

Decía Chardon que gran parte del progreso agrícola de los Estados Unidos era debido a las enormes transformaciones en cultivos y métodos, origen de nuevas semillas y variedades, estudios y control de enfermedades y análisis sistemático de suelos realizados en las estaciones experimentales (Chardon, 1930: 20); por lo que instaba a que los trabajos de Java, Hawái y Puerto Rico fuesen imitados por Colombia. El departamento no podía esperar -insistía Chardon- a que los agricultores iniciaran con las pruebas de semillas y nuevos procedimientos, pues esto siempre llevaría al fracaso, ya que ellos no tenían la preparación científica suficiente.

Tanto los desarrollos tecnológicos del cultivo de la caña como del ganado vacuno y caballar deberían ser adelantados en estaciones experimentales. La misión reconoció la

11. Bolívar (2008) plantea el consumo de carne como un problema de higiene y, por tanto, de transformación moral en Colombia a comienzos del siglo xx. Las memorias de los ministros de Instrucción Pública en la primera mitad del siglo revelan una preocupación por la forma como los alimentos y, en general, el cuidado físico incidían en el mejoramiento moral de los colombianos. Los discursos y saberes higiénicos fueron reemplazando los de urbanidad de finales del siglo XIX y al hacerlo convirtieron la preocupación por la alimentación en una discusión sobre propiedades y fisiologías nutricionales y requerimientos para el progreso. Este discurso moral sobre el cuerpo fue cediendo su lugar a los discursos médicos sobre el cuidado corporal y la buena nutrición. 
excelente ubicación geográfica de la Estación de Palmira, así como sus condiciones de topografía y suelo; y estableció un programa de edificaciones con sus costos aproximados y una plantilla de personal calificado conformada por técnicos extranjeros de la más alta calidad $^{12}$.

Las recomendaciones de la misión y los resultados de las investigaciones efectuadas por la Estación Agrícola comenzaron a observarse en el cultivo de la caña de azúcar: se introdujeron nuevas variedades enviadas desde Puerto Rico, siendo las más exitosas las POJ 2878, 2714 y 228. Además, empezaron los cambios en la preparación del suelo, en las técnicas de siembra y en el sistema de riego. La innovación en el proceso productivo, liderada por los ingenios Manuelita, Riopaila y Providencia, fue bastante heterogénea debido a la variabilidad de las condiciones biofísicas y climáticas del valle geográfico. Con el proceso de modernización (intensificación) de la producción de caña, apareció el mosaico, la primera enfermedad que tuvo verdadera incidencia económica en el cultivo ${ }^{13}$, lo que obligó a los cultivadores a reemplazar las variedades criollas o cristalinas, sembradas hasta 1930, por la POJ 2878, resistente a dicha enfermedad.

En 1936 Chardon regresó al departamento por solicitud del gobierno nacional, para evaluar los daños ocasionados por el mosaico. Su evaluación señaló la urgencia de erradicar los cultivos infestados, crear una misión técnica azucarera (adscrita al Ministerio de Agricultura, institución creada por sugerencia de los expertos de la misión de 1930 quienes recomendaron que los asuntos agrícolas no siguieran en manos del de Industrias; Chardon, 1930: 18) y una estación experimental con subestaciones en regiones cañeras que facilitasen el estudio permanente de los cultivos. Tras ocho años de su primera visita, Chardon dio una conferencia sobre el mosaico ante la Sociedad de Agricultores de Colombia. En ella explicó, reforzando lo expresado en el informe de 1930, que la agricultura progresaba de dos formas: por observación (método primitivo que databa de los tiempos bíblicos), y por experimentación científica (método con apenas cincuenta años de aplicación, pero cuyos resultados positivos eran superiores a los de tres mil años de observaciones). El científico exigía estaciones experimentales, especialistas y buenas bi-

12. Chardon (1930: 22) apuntaba que en Colombia no había técnicos cualificados, puesto que su juventud prefería carreras elegantes y de distinción, como la abogacía, la medicina, las bellas letras y la política. Había que orientarla, entonces, hacia estudios de ingeniería, agronomía, química y veterinaria; en el uso del compás y el teodolito; en el estudio de las ciencias físico-químicas y sus múltiples aplicaciones a la vida moderna; en el de las sabrosas ciencias naturales, tan ricas en sorpresas útiles.

13. El mosaico es una de las enfermedades más ampliamente distribuidas en el mundo, causada por el virus del mosaico común de la caña de azúcar (SCMV) que es miembro del grupo de los potyvirus y afecta las hojas de tallos maduros produciendo decoloraciones de la lámina foliar (cenicaña). 
bliotecas tecnológicas, y argumentaba que la producción cañera requería un instituto central de investigaciones con subestaciones regionales en el país, encargado de coordinar y acelerar la renovación de la agroindustria, para convertirla en una actividad especializada, eficaz y efectiva.

La empresa científica de Chardon y su grupo resultó de gran importancia, puesto que por primera vez se efectuaba la evaluación y el diagnóstico del estado de la productividad agropecuaria departamental de las primeras décadas del siglo xx a la luz del cientificismo occidental. Estas y otras acciones fueron el preludio de la toma de decisiones técnico-políticas para el agro colombiano.

\section{CHARDONY LA INSTITUCIONALIZACIÓN DE LA INNOVACIÓN AGRÍCOLA EN LA REGIÓN}

El anhelo de los países latinoamericanos por modernizar su agricultura alentó la entrada del dinero y de la ciencia estadounidenses, sin reparar en el tiempo que podría tomar la implantación de las innovaciones ni las características propias de cada región del país. Este interés era apoyado por academias, élites, productores y gobiernos, por lo que se asume que la ideología tecnocrática del desarrollo agrícola (presente en la región desde el siglo $\mathrm{XIX})^{14}$ se consolidó en el siglo XX mediante revistas y periódicos, centros de enseñanza ${ }^{15}$, asociaciones agrícolas y estaciones experimentales (Cuvi, 2011: 166).

En 1913 se fundó la Escuela Regional Agrícola en Palmira, pero solo empezó a funcionar en 1928, en el marco de la regionalización contemplada en la ley 41 de $1926^{16}$ so-

14. Durante el siglo XIX no hubo en Colombia ciencias agropecuarias. En 1878 se crea la Sociedad de Agricultores de Colombia (SAC) con el objetivo de modernizar el campo mediante la adopción de la agricultura científica a través del impulso de la producción agrícola y pecuaria, como motores de progreso y fuente de acumulación de riqueza. En 1879 se establece la quinta de aclimatación, experimentación y enseñanza de la agricultura (PIÑEIRO et al., 1982: 238); y en 1897 comienzan a registrarse los estudios agropecuarios (veterinaria y agronomía) en calidad de especialidades de las escuelas de ciencias naturales. En 1904 la Universidad de Antioquia abre la Escuela de Agronomía y posteriormente se crea la primera Escuela de Agricultura Tropical y Veterinaria, en Medellín, que luego se trasformaría en la Facultad Nacional de Agronomía (BEJARANO, 1987: 129, 132, 154).

15. La primera institución de educación agrícola superior que se crea en América Latina es la Escuela Nacional de Agricultura de San Jacinto, o Chapingo, en México, en 1854; seguida por la Escuela Agronómica de Bahía, en Brasil, y la Facultad de Agronomía de la Plata, en Argentina, fundadas en 1877 y 1882, respectivamente. Al mismo tiempo iniciaban los land grand colleges de los Estados Unidos.

16. De forma paralela a la emisión de la ley 41, el Estado colombiano emitió el decreto y la ley 3 de emergencia económica de 1926, por la cual se redujeron al mínimo los gravámenes que pesaban sobre 
bre el fomento de la industria del algodón en Colombia, bajo el nombre de Granja Agrícola Experimental de Palmira (luego Estación Experimental), entidad que se convertiría en la semilla de la actual Universidad Nacional-Sede Palmira. La Estación se constituyó en la protagonista indiscutible en materias agrícolas de la América tropical (Chardon, 1930: 337): el verdadero nervio y cerebro de los trabajos agrícolas (Ibid.: 21).

Las recomendaciones de la Misión Chardon en el ámbito regional contrastaban con la sugerencia de esta al Gobierno nacional sobre la urgencia de preparar un proyecto de ley que reorganizara los servicios agrícolas nacionales creados por la ley 74 de 1926 . Para Chardon, todo el trabajo experimental desarrollado in situ debería ser entregado, por medio de un contrato de varios años, al Tropical Plant Research Foundation de Washington, institución de reconocida reputación científica, con amplia experiencia en trabajos tropicales y con el respaldo del Departamento de Agricultura de los Estados Unidos y de la Unión Panamericana. La misión consideraba que esta era la forma más viable de darle las necesarias estabilidad y continuidad a los trabajos de experimentación.

Aun así, la promulgación de la ley 132 de 1931 facilitó la irrupción de la agricultura científica en el Valle del Cauca, puesto que permitió a los pioneros instaurar en 1934 un instituto agrícola (Valencia \& Acevedo, 2010: 84-88), que diez años después se transformó en la Facultad de Agronomía del Valle, que haría parte de la Universidad Nacional-Sede Palmira.

La Estación Experimental funcionó como entidad departamental hasta 1938. La promulgación de la ley 128 del fomento del dulce de 1937 provocó su compra por parte del Ministerio de Agricultura, convirtiéndose en el Centro Nacional de Investigaciones Agropecuarias de Palmira (CNIAP), donde con asesoría de técnicos extranjeros se intensificaron las investigaciones para producir variedades híbridas que se adaptaran a suelos y climas nacionales (Ramos, 2005).

Así las cosas, la modernización de la educación agropecuaria en el país en las primeras décadas del siglo Xx fue la resultante de cumplir con los requerimientos y las obligaciones derivadas de las políticas para el desarrollo de América Latina, las mismas que impulsaban las misiones extranjeras como entes promotores de la política estadounidense

la importación de alimentos, para frenar el alza interna de precios. Según funcionarios locales de la época, afectó a los ingresos de los propietarios agrícolas de la región, ocasionando la desaparición de cultivos como el arroz y de pequeños trapicheros que no podían competir con la naciente industria azucarera (DURÁN, 1929). Esta coyuntura también propicia el inicio del proceso de transformación de los métodos y técnicas de producción con miras a abaratar costos y mantener las tasas de ganancia por la vía de los aumentos de la productividad del trabajo (ROJAS, 1983: 21). 
de comienzos de siglo. La Misión Chardon dejó las bases para el futuro diseño de proyectos que facilitaron la creación de instituciones científicas encargadas de desarrollar procesos de innovación, desarrollo y cambio tecnológico para el sector agropecuario, que se perfeccionaron en las décadas de los cincuenta, sesenta y setenta bajo el influjo de la revolución verde, y que constituyeron el germen del futuro clúster azucarero conformado a finales del siglo $\mathrm{xx}$.

Desde los años cuarenta, los ingenios tuvieron asesores extranjeros, práctica que después de los años cincuenta se incrementó; de modo que por muchos años varias compañías consultoras en el ámbito industrial asesoraron a los ingenios vallecaucanos, entre ellas Hawaian Agronomics, la compañía puertorriqueña Abarca y Lousiana Arthur Keller Corp (Guardiola, 1995: 11). Las metas modernizadoras no sólo se diseñaron para aumentar el rendimiento interno de sus empresas, sino que instaron la posterior creación de instituciones como: la Asociación de Cultivadores de Caña (Asocaña, 1959); Colombiana de Mieles (Colmieles, 1960); la Sociedad de los Ingenios para Desarrollos Industriales y Comerciales (DICSA); la Asociación Colombiana de Productores y Proveedores de Caña (Procaña, 1973); la Asociación Colombiana de Técnicos de la Caña de Azúcar (Tecnicaña); y el Centro de Investigación de la Caña de Azúcar (Cenicaña, 1977).

Las políticas públicas que permitieron todos estos cambios involucraron a funcionarios de la administración departamental, funcionarios de carácter nacional e internacional, así como también a empresarios locales y a personal técnico internacional cualificado. Estos actores, que bien pueden catalogarse como élites del poder económico, político y científico, fueron responsables de desarrollar acciones afirmativas del Estado en lo regional-local para la transformación socioecológica del valle geográfico, lugar que pasó de una producción agropecuaria comercial a una agroindustrial.

\section{LAS MISIONES POSTERIORES A CHARDONY SU HUELLA EN EL TERRITORIO VALLECAUCANO}

La política agrícola colombiana que emergió después de los años treinta correspondió a las relaciones establecidas históricamente entre Estados Unidos y América Latina ${ }^{17}$. La

17. MARQUARDT (2009: 199-201) afirma que después de que los Estados pioneros de la revolución industrial se habían instaurado y solidificado, empezó una tendencia profunda de la transformación fósil-energética e industrial en otras partes del mundo y muy especialmente en América Latina. El bloqueo de las vías marítimas hasta Europa en la Primera Guerra Mundial (1914-1918), la crisis del sistema internacional capitalista o Gran Depresión (1929-1932) y luego la Segunda Guerra Mundial, marcaron una de las mayores crisis del metabolismo global (flujos de energía y materiales) lo que llevó 
estrategia norteamericana en la segunda década del siglo xx tenía, por lo menos, tres objetivos: a) estimular las exportaciones al área para contrarrestar los efectos de la superproducción interna que se empezaba a sufrir y que efectivamente conduciría a la crisis económica de 1930; b) desplazar la competencia europea y japonesa del continente y asegurar su hegemonía; y c) apoderarse así de un amplio mercado de capitales de inversión directa e indirecta que le asegurara el control económico de la región. Por esta razón, toda la diplomacia norteamericana en Colombia se orientó en este período a la apertura comercial a través del establecimiento de tratados de libre comercio con el país y al control de la producción petrolera (Ocampo, 2009). Posteriormente, en el marco de la guerra fría, Estados Unidos delineó una serie de políticas y estrategias de contención del comunismo. La política del Buen Vecino, los préstamos del Banco de Exportaciones e Importaciones, el Consejo de Tenedores de Bonos Extranjeros y el programa de Tratados de Comercio fueron medidas tendentes a estabilizar la zona latinoamericana en función de los intereses económicos y políticos estadounidenses (Carbone, 2010:3).

Las buenas relaciones del entonces ministro de Colombia (Enrique Olaya Herrera) ante el Gobierno de Washington permitieron que el Partido Liberal volviera al poder en el alba de la tercera década del siglo xx, comenzando así la que luego fue llamada la $R e-$ pública liberal (comprendida entre 1930 y 1946), periodo en que fue notoria la intención de la dirigencia política de educar campesinos y formar ciudadanos para afrontar la modernización del país. Los gobiernos que orientaron las políticas durante los 16 años de hegemonía liberal (Olaya Herrera, López Pumarejo, Santos Montejo y, por segunda vez, López Pumarejo) tramitaron importantes reformas, como la educativa, la fiscal y la agraria, que encontraron entre las élites conservadoras, la Iglesia y los hacendados los principales opositores a esas iniciativas de cambio. La llamada Revolución en Marcha del primer gobierno lopista buscó impactar seriamente en la educación obrera y campesina en Colombia a través de programas de alfabetización para niños y jóvenes, así como escuelas nocturnas de artes y oficios para adultos (Ardila, 2005). Sin embargo, aunque el discurso liberal defendió con vehemencia la enseñanza práctica en técnicas agrícolas en el campo colombiano, la escasa escolarización lograda -evidenciada en el bajo número de matriculados, o la alta inasistencia y deserción durante cada año lectivo- puso de manifiesto dos situaciones que impidieron el protagonismo de la base campesina colombiana en las ideas progresistas del siglo xx: a) la pobreza rural, que impedía al padre de familia campesino enviar a sus hijos a la escuela, pues ellos constituían una mano de obra disponible, gratuita y necesaria para conseguir el sustento diario; y b) la gran influencia que tenía la Iglesia sobre estas sociedades campesinas, marcadamente tradicionales y renuentes

a los Estados hispanoamericanos a desarrollar un constitucionalismo económico y social, altamente dependiente de los Estados Unidos. 
a las innovaciones, al intentar mantener el statu quo apelando a la fe como forma de resistencia a la transformación del agro colombiano ${ }^{18}$. La tensión con la Iglesia y la división del partido hicieron que los liberales perdieran la presidencia en el cuatrienio 19461950 y, con ello, la oportunidad de profundizar en las reformas agrarias y socioeconómicas impulsadas desde la República liberal.

Por otra parte, el modelo de revolución verde marcaría una nueva fase de modernización agrícola con el desarrollo y cultivo de variedades genéticamente modificadas y la fertilización y el control de plagas y enfermedades mediante la alternativa química (Picado, 2014: 490-521). En este contexto, vinieron otras misiones y visitas de académicos norteamericanos de distintas disciplinas; como las del sociólogo rural y profesor de la Universidad de Luisiana, Thomas Lynn Smith (1943) (Lorek, 2013), la de Lauchlin Currie (1950), la misión liderada por David Lilienthal, en 1954, e incluso las intervenciones de las fundaciones Rockefeller, Ford y Kellog, que contribuyeron a gestar el Centro de Investigación de Agricultura Tropical (CIAT), en 1967, como punta de lanza de la revolución verde dentro de la estructura internacional de institutos de investigación del Consultive Group on International Agricultural Research (CGIAR) (Picado, 2008: 55).

Todos ellos ratificaron y aumentaron las recomendaciones técnicas y políticas elaboradas por la Misión Chardon para la modernización e integración económica de la agricultura. En consecuencia los gobiernos regionales en las décadas del cincuenta al ochenta diseñaron estrategias para el control de inundaciones e irrigación de tierras agrícolas; incentivaron la intensificación de la ganadería en la ladera al tiempo que impulsaron un plan de obras en las tierras planas que inclúa: construcción de represas, apertura de canales de irrigación, desecación de tierras anegadizas y ciénagas para recuperar miles de hectáreas de tierra ociosa (CVC, 2004: 63).

Parte sustancial del desarrollo regional se apoyó en el capital y la energía humana del sector privado, de modo que las explotaciones agrícolas de pequeños y grandes comercios al detalle y la construcción de fábricas complementaron el centro del desarrollo agroindustrial de las empresas azucareras. Al Estado, entre tanto, le correspondió la construcción de carreteras, ferrocarriles, facilidades portuarias, aeropuertos y hospitales, así como la electrificación, la puesta en marcha de la navegación fluvial y la experimentación

18. Mora (1995) encuentra que Veritas, el boletín del santuario de Nuestra Señora de Chiquinquirá, publicado con fecha del 22/09/1937 (p. 3), decía: El Gobierno tiene una frase consagrada para justificar sus actuaciones. Hay que desfanatizar a este pueblo. Y por desfanatizar entiende arrebatar a Cristo de la escuela, paganizar la juventud, corromper con la escuela mixta, las lecturas procaces, las láminas indecentes. Y cuando a un pueblo se le quita el freno de la religión y se le educa en el materialismo crudo, no hay que esperar más que una generación de asesinos e incendiarios. 
agrícola y forestal. En este contexto Lilienthal expresaba que, como sucedió en el valle del Tennessee ${ }^{19}$, después de una inversión inicial del Gobierno, afloraría una gran actividad privada en todos los aspectos de la economía regional vallecaucana.

A partir de 1930 las acciones del Estado en su escala regional junto con las del sector privado tendieron a modernizar la producción agropecuaria desde las ventajas comparativas del terreno y la especialización del monocultivo; todo ello fundado en el cientifismo occidental hegemónico, que marcó la fase de despegue de la transición socioecológica que se extendería hasta la década de los setenta, constituyéndose en el inicio de la gran transformación del territorio vallecaucano, lo que hizo que productivamente la región transitara de una producción más tradicional y orgánica a una industrial basada en el uso de combustibles fósiles.

Este periodo marcó un hito importante en la historia ambiental de la región. La coincidencia de una serie de factores, procesos e imaginarios fue determinante en la dirección que tomó la transformación del valle geográfico. Imaginarios contrapuestos sobre la naturaleza y el progreso marcaron esta época. Un imaginario preponderante y superlativizado por gran parte de la historiografía regional refiere a una naturaleza indomable, caracterizada -según palabras de Phanor Eder- por una vegetación salvaje de tupidas y selváticas lianas, poblada de micos y animales indómitos y por ciénagas insalubres $y$ miasmáticas, incubadoras de endemias tropicales que diezmaban la población que requería ser domesticada, domeñada, en beneficio de una región relegada y atrasada (Plazas y Perry, 1964).

De allí que este tipo de naturaleza, que debía ser dominada a través de la modernización de su estructura agropecuaria, justificaba la urgencia de cualquier iniciativa agroindustrial. La explotación de la ganadería y de la agricultura con métodos científicos fue el propósito de hacendados, comerciantes extranjeros y empresarios. Estos, justificados por los discursos referentes a la paz política y a las iniciativas para la construcción de un sistema moderno de comunicaciones, impulsaron el abandono en el pasado de las vicisitudes que impidieron el tránsito por las sendas del progreso y de la civilización (Londoño,

19. La cuenca del río Tennessee abarca dos tercios de Tennessee y parte de seis estados más. En 1933 se creó una corporación federal autónoma, la Tennesse Valley Authority, para la gestión de la cuenca. El objetivo era proporcionar navegación, control de inundaciones, generación eléctrica, producción agrícola y el desarrollo económico al valle del Tennessee, zona afectada por la Gran Depresión. En los primeros años se construyeron presas que obligaron a desplazarse a más de quince mil familias. La red de presas y los canales de navegación construidos ayudaron al desarrollo económico del valle, aunque también provocaron grandes impactos ambientales. 
2010: 22). Sin embargo, este imaginario de progreso - propio de la élite ilustrada ${ }^{20}$ y de algunos empresarios- tenía un gran impedimento: la gente que habitaba el territorio.

Carlos Durán Castro así lo planteaba en 1928 (Durán, 1929: 115):

El pueblo que habita el Valle del Cauca, por ciertos aspectos no es adecuado para la agricultura. La herencia que lleva arraigada a la vida pastoril fácil y sin lucha industrial intensa, lo ha desadaptado, para la brega que impone la agricultura y por ese motivo, en el cambio que ocurrirá del pastoreo a la intensificación de la producción del suelo, es muy fácil que el caucano quede reemplazado en el dominio y explotación de la tierra por razas más luchadoras como la antioqueña y por inmigrantes extranjeros.

Asimismo, en el mensaje del gobernador del Valle del Cauca a la Asamblea Departamental, en el que justificaba la necesidad de crear la Cámara de Agricultura del departamento, decía:

En las modernas organizaciones gremiales radica toda la fuerza que alcanzan hoy los éxitos del comercio [...] si no hay quien dirija e ilustre al pueblo cultivador, seguirá el mismo empirismo infecundo que hasta el presente nada ha cosechado, sino el fracaso para quienes, animados de los mejores deseos, ignoran las orientaciones científicas que rigen este ramo de la riqueza pública y privada [...] esta la causa principal de la carencia de agricultores idóneos (Vernaza, 1925).

Las nuevas misiones de expertos, seguidores de la senda trazada por Chardon, sólo volvieron a llenar de argumentos los intereses particulares de la élite política, económica y empresarial del Valle del Cauca, impulsadora de nuevas legislaciones que permitirían la implementación parcial de las recomendaciones de la Misión Chardon, afectando así las formas productivas agrícolas tradicionales en cultivos como el del arroz, el cacao y el tabaco. Otros afectados fueron los pequeños trapicheros, quienes por sus estilos y formas productivas no podían competir con sus contrapartes, los nacientes empresarios modernos.

La era liberal marcó lo que, sin duda, fue el inicio de la mayor transformación ambiental en el suroccidente colombiano desde la conquista de América. El logro central de las ciencias agropecuarias antes de la Gran Depresión fue, como apunta McCook, una

20. Los principales exponentes de esta visión fueron Ciro Molina Garcés (1891-1953) y Carlos Durán Castro (1897-1993), personajes y empresarios representativos de la élite vallecaucana, quienes después de la Misión Chardon ostentaron altos cargos públicos nacionales y departamentales. 
reorganización física y cognitiva de la naturaleza tropical y sus paisajes silvestres y agrícolas. Tanto las políticas públicas como el entramado institucional permitieron hacer efectivo el llamado de Chardon -y, por ende, del Gobierno de Estados Unidos- a los jóvenes colombianos a encontrar los inmensos placeres intelectuales poniéndose en contacto con las fuerzas misteriosas de la naturaleza, arrancándoles sus secretos y poniéndoles al servicio de su país y de la humanidad ${ }^{21}$. Colombia adoptó, como otros países de América Latina, el lema, del sentido práctico; el único que tanto entonces como ahora, según la visión estadounidense, hacía a los pueblos grandes, poderosos y felices. No obstante, la realidad socioecológica del valle del Cauca fue otra. El rico ecosistema de bosque seco tropical predominante en la zona plana delValle del Cauca hasta el siglo XIX, en la segunda mitad del siglo XX se transformaría en un gran desierto verde de caña de azúcar.

\section{CONCLUSIONES}

A partir de la década de los treinta del siglo $\mathrm{xx}$, las autoridades políticas departamentales delValle del Cauca emprendieron la primera fase del esfuerzo gubernamental para la tecnificación del sector agropecuario. La Misión Chardon fue la estrategia del estado regional que facilitó la incorporación de métodos y técnicas productivas de carácter científico, innovaciones introducidas y reforzadas posteriormente con las propuestas y recomendaciones de las entidades extranjeras (misiones y universidades). En este marco, las sugerencias de la Mision Chardon contribuyeron a modelar la modernización de las formas productivas en pro de la agroindustria, lo que devino en la sujeción de la mano de obra, el cambio en los usos del suelo y el aprovechamiento industrial del agua superficial y subterránea. Si bien los técnicos de la misión visualizaron el gran potencial productivo del valle geográfico del río Cauca en el ramo azucarero, se quedaron cortos con respecto a la magnitud productiva de esta región. En la década de 1980 el valle producía 125 toneladas de caña por hectárea y 9,70 toneladas de azúcar por tonelada de caña, la mayor alcanzada con este cultivo en el mundo (Asocaña, 1999).

Las granjas experimentales agrícolas -y las instituciones que se crearon en el Valle del Cauca durante las décadas del treinta al cincuenta-, por recomendación de Chardon, fueron las avanzadas estatales encargadas de la investigación y el desarrollo para el mejoramiento de la producción de semillas, fertilizantes, pesticidas, y la innovación en técnicas de cultivo, riego y mejoramiento genético de plantas y animales. Estas instituciones, ade-

21. Esta visión de CHARDON (1947: 98) aparece amplificada en otra de sus publicaciones al referirse a los primeros cronistas que visitaron América como devotos soldados del gran ejército de la ciencia $[\ldots]$ quienes pasaron a la historia como los mártires de una causa noble. 
más, se encargaron de apoyar a los agricultores en los procesos de tecnificación de sus predios; y difundieron información sobre mejoramiento y optimización agropecuaria, incidiendo en la transformación de los procesos productivos. Las granjas experimentales con el respaldo de la gobernación departamental, las secretarías de Hacienda, Agricultura, y la de Industria y Comercio, fueron las instituciones de desarrollo, investigación e innovación técnico-agropecuaria que dieron las bases del impulso económico al departamento.

Es justamente por lo anterior que la Misión Chardon puede considerarse la primera política pública departamental con objetivos de innovación productiva en pro de un cambio tecnológico, que alimentaría al sector agropecuario regional, insertándolo verticalmente con la caña de azúcar al sistema productivo global. Es por ello que se considera que sin la agencia de las políticas públicas agropecuarias -derivada de la iniciativa del gobernador Carlos Holguín Lloreda, con apoyo de su secretario de Industrias, Ciro Molina Garcés, y el cuerpo diplomático nacional- la transformación de los modos de explotación económica y sus efectos en la transición socioecológica quizás hubieran tardado mucho más.

Los agricultores, los gremios agrícolas y los diversos gobiernos (liberales y conservadores), tanto nacionales como locales, se mantuvieron fieles a sus propios intereses políticos y económicos, desestimando las recomendaciones que les pudieran resultar adversas y tomando en consideración solo aquellas que redituaran en mayores ganancias sin tomar en consideración los posibles efectos sociales y ecológicos de sus acciones. Los paisajes culturales en mosaico que habían generado históricamente las formas tradicionales de manejo del agroecosistema fueron alterados rápidamente con efectos severos sobre la diversidad agrícola, biológica y genética; la morfología del paisaje y los flujos hídricos y de nutrientes (pérdida en la calidad y fertilidad de los suelos).

En los actuales momentos históricos sería conveniente observar con detenimiento qué actores socioeconómicos, qué modelos técnico-políticos y qué nuevas ideas difusionistas impulsan las últimas innovaciones agrícolas en el contexto internacional, y cómo estas inciden en la extensión galopante de nuevas especies agrícolas (como la palma africana), que traen como iniciativa la implantación de otros monocultivos en contextos regionales y nacionales con la promesa de modernizar el campo y sacar de la pobreza a los habitantes raizales de dichos espacios territoriales.

\section{AGRADECIMIENTOS}

Esta investigación fue apoyada por el Consejo de Investigación en Ciencias Sociales y Humanas de Canadá (SSHRC, por su sigla en inglés) en el marco del programa de Sub- 
venciones de Consorcios. Agradecemos a la historiadora Sonia Jaimes por las discusiones teóricas y sus aportes en la redacción de una versión germinal de este documento. A Maria José Larrota y Mauricio Hernández por su apoyo técnico, y al Ingenio Manuelita por permitirnos el acceso a su archivo histórico. Finalmente, agradecemos a los dos revisores anónimos de Historia Agraria por sus comentarios y sugerencias.

\section{REFERENCIAS}

Arango, M. (2005). Influencia del discurso del desarrollo y las misiones estadounidenses en la formación agronómica. Tesis de maestría. Medellín: Universidad Nacional de Colombia.

Ardila, B. (2005). Alfonso López Pumarejo y la revolución en marcha. Credencial Historia, (192). http://www.banrepcultural.org/biblioteca-virtual/credencial-historia/numero-192/alfonso-lopez-pumarejo-y-la-revolucion-en-marcha

ARDILA, F. (2013). Reflexiones sobre el imperialismo norteamericano: La política agraria colombiana y la influencia estadounidense en la década de 1930. Historia Crítica, (51), 171-195.

AsocaÑa (1999). Informe anual con aspectos generales del sector azucarero colombiano 1999-2000. Asocaña: Cali.

Bejarano, J. A. (1987). Las ciencias agropecuarias hasta mediados del siglo Xx: Ensayos de historia agraria colombiana. Bogotá: CEREC.

Bolívar, I. J. (2008). Discursos estatales y geografía del consumo de carne de res en Colombia. En A. G. Flórez Mondragón (Ed.), El poder de la carne: Historias de ganaderías en la primera mitad del siglo XX en Colombia (pp. 230-289). Bogotá: Editorial Pontificia Universidad Javeriana.

Broeck, A. M. van \& Molina, L. F. (1997). Presencia belga en Colombia: Ciencia, cultura, tecnología y educación. Boletín Cultural y Bibliográfico, 34 (44), 47-71.

Carbone, V. (2010). Cuando la Guerra Fría llegó a América Latina: La Política Exterior Norteamericana hacia Latinoamérica durante las presidencias de Eisenhower y Kennedy (1953-1963). Buenos Aires: Centro Argentino de Estudios Internacionales.

CHARDon, C. E. (1930). Reconocimiento agropecuario del Valle del Cauca: Informe emitido por la Misión agrícola puertorriqueña, dirigida por el Honorable Carlos Eugenio Chardon y presentado al Gobernador del Departamento del Valle del Cauca en Colombia. San Juan de Puerto Rico.

Chardon, C. E. (1941). Viajes y naturaleza. Caracas: Sucre.

CHARDOn, C. E. (1947). Longevity and Casualties among Naturalists in Tropical America. The Scientific Monthly, 64 (3), 198-207.

Cock, J. H. (1999). Informe del director: Informe anual Cenicaña. Cali: Cenicaña. 
Corporación Autónoma Regional del Valle del Cauca (CVC) (2004). Génesis y desarrollo de una visión de progreso: CVC 50 años. Cali: Corporación Autónoma Regional del Valle del Cauca.

Cuvi, N. (2011). «Dejen que el diablo haga lo demás»: La promoción de productos complementarios en América Latina durante la década de 1940. Historia Crítica, (44), 158181.

Drake, P.W. (1989). The Money Doctor in the Andes:The Kemmerer Missions, 1923-1933. Durham: Duke University Press.

DurÁn, C. C. (1929). Porvenir de la agricultura en el Valle del Cauca. En E. López (Ed.), Almanaque de los hechos colombianos. Cali.

Flórez, M. A. (2008). Dime qué comes y te diré quién eres. En A. Flórez MondraGÓN (Ed.), El poder de la carne: Historias de ganaderías en la primera mitad del siglo XX en Colombia (pp. 368-439). Bogotá: Editorial Pontificia Universidad Javeriana.

GonZÁLEZ, J. M. (2001). Una aproximación al estudio de la transformación ecológica del paisaje rural colombiano: 1850-1990. En G. A. PALACIO (Ed.), Naturaleza en disputa: Ensayos de historia ambiental en Colombia, 1850-1995 (pp. 75-116). Bogotá: Universidad Nacional de Colombia.

GuARDiola, J. (1995). Avances tecnológicos entre 1950 y 1980. En D. CASSALETT, J. ToRRES \& C. I. ECHEVERRY (Eds.), El cultivo de la caña en la zona azucarera de Colombia (pp. 9-21). Cali: Cenicaña.

KeRn, F. D. (1965). Dr. Carlos E. Chardon. Mycología, 57 (6), 839-844.

LONDOÑo, J. E. (2010). De «región decimonónica a región nacional»: Instituciones, ordenanzas y presupuestos departamentales en la configuración del departamento deVa1le, 1910-1948. Segundo Congreso Latinoamericano de Historia Económica y Simposio Investigaciones Recientes en Historia Económica de Colombia, Siglos XIX y XX. Ciudad de México, 3-5 de febrero.

LOREK, T.W. (2013). Imagining the Midwest in Latin America: US Advisors and the Envisioning of an Agricultural Middle Class in Colombia's Cauca Valley, 1943-1946. Historian, 75 (2), 283-305.

Mallama, W. (1996). Proceso de industrialización en el municipio de Palmira, 1920-1970. Cali: Marden.

MARQUARDT, B. (2009). La revolución industrial en América Latina (1840-2009): Una interpretación desde la perspectiva de la teoría de sistemas de energía. En R. P. SIEFERLE \& B. MARQUARDT (Eds.), La revolución industrial en Europa y América Latina: Interpretaciones ecohistóricas desde la perspectiva de la teoría de sistemas de energía y del metabolismo social. Bogotá: Universidad Nacional de Colombia.

McCook, S. G. (2002). States of Nature: Science, Agriculture and Environment in the Spanish Caribbean, 1760-1940. Austin: University of Texas Press. 
MCNeILl, J. R. (2005). Naturaleza y cultura de la historia ambiental. Revista Nómadas, (22), 2-25.

MoRA, J. (1995). La Iglesia frente a las reformas educativas de los años treinta en México y Colombia. Revista Colombiana de Educación, (30).

OcAmpo, J. F. (2009). El Tratado de Comercio de 1935 con Estados Unidos: Antecedente para no repetir. Deslinde, (37), 1-11.

PALACIO, G. (1998). La naturaleza en disputa:Tierra, territorio y biodiversidad. En J. M. González Scobie, G. A. PAlacio et al. (Eds), La manzana de la discordia: Debate sobre la naturaleza en disputa (pp. 1-40). Bogotá: Ecofondo/Tercer Mundo.

Palacios, M. (2011). ¿De quién es la tierra?: Propiedad, politización y protesta campesina en la década de 1930. Bogotá: Fondo de Cultura Económica/Universidad de los Andes.

Pearse, A. S. (1926). Colombia, with Special Reference to Cotton: Report of the fourney of the International Cotton Mission through the Republic of Colombia, February-April 1926. Manchester: International Federation of Master Cotton Spinners/Manufacturers Association.

PiCADO, W. (2008). Ciencia y geopolítica en los orígenes de la Revolución Verde. Revista de Ciencias Ambientales, 36 (1), 46-56.

PICADO,W. (2014). Los significados de la revolución: Semántica y temporalidad y narrativa de la Revolución Verde. HALAC. Historia Ambiental Latinoamericana y Caribeña, 3 (2), 490-521.

Piñeiro, M., Fiorentino, R., Trigo, E., Balcázar, A. \& Martínez, A. (1982). Articulación social y cambio técnico: La producción de azúcar en Colombia. San José: Instituto Interamericano de Cooperación para la Agricultura. (Investigación y Desarrollo, 7).

Plazas y Perry (1964). Manuelita: Una industria centenaria, 1864-1964. Bogotá: Argra. Ramos, O. G. (2005). Caña de azúcar en Colombia. Revista de Indias, LXV (233), 49-78. RoJAS, J. M. (1983). Empresarios y tecnología en la formación del sector azucarero en Colombia, 1860-1980. Bogotá: Fondo de Promoción de la Cultura del Banco Popular/Universidad del Valle. (Sociedad y Economía en el Valle del Cauca, 5).

STERN, S. J. (1987). Feudalismo, capitalismo y el sistema mundial en la perspectiva de América Latina y el Caribe. Revista Mexicana de Sociología, 49 (3), 3-58.

Topik, S. \& Wells, A. (1998). The Second Conquest of Latin America: Coffee, Henequen, and Oil during the Export Boom, 1850-1930. Austin: University of Texas Press.

VALENCIA, N. F. \& ACEVEDO, A. (2010). Origen de la educación agrícola superior en el Valle del Cauca, 1910-1934. Historelo, 2 (3), 67-93.

Valencia, N. F. \& Carmona, G. (2015). Universidad Nacional de Colombia, Sede Palmira: Génesis agrícola e impacto social institucional (1900-1944). Acta Agronómica, 64 (3), 281-295. 
VerA, A. (1996). La inversión extranjera y el desarrollo competitivo en América Latina y el Caribe. Revista de la CEPAL, (60), 129-150.

VernaZA, J. I. (1925). Informes varios al gobernador del Valle del Cauca: Mensaje del gobernador del Valle del Cauca a la Asamblea Departamental. Cali: Carvajal \& Cía. 